\title{
Defining Supply Chain Visibility for Industrial Construction Projects
}

\author{
Vineeth Dharmapalan ${ }^{1 *}$, William J. O'Brien ${ }^{1}$ and Douglas J. Morrice ${ }^{2}$ \\ ${ }^{1}$ Department of Civil, Architectural and Environmental Engineering, The University of Texas at Austin, Austin, TX, United States, \\ ${ }^{2}$ Department of Information, Risk, and Operations Management, The University of Texas at Austin, Austin, TX, United States
}

OPEN ACCESS

Edited by:

Zhen Chen,

University of Strathclyde,

United Kingdom

Reviewed by:

Andrew Agapiou,

University of Strathclyde,

United Kingdom

Ali Akbar Nezhad,

Boral Limited, Australia

*Correspondence:

Vineeth Dharmapalan

vineeth.dp@utexas.edu

Specialty section:

This article was submitted to

Construction Management,

a section of the journal

Frontiers in Built Environment

Received: 09 January 2021 Accepted: 13 September 2021 Published: 28 September 2021

Citation:

Dharmapalan V, O'Brien WJ and Morrice DJ (2021) Defining Supply

Chain Visibility for Industrial

Construction Projects.

Front. Built Environ. 7:651294.

doi: 10.3389/fbuil.2021.651294
Good Supply Chain Visibility (SCV) is vital for on-time delivery and installation of materials on industrial construction projects. SCV is possible via the exchange of information about materials in the supply chain. Prior academic research has highlighted the importance of SCV. However, the literature lacks the detailed definition of visibility that can be easily applied to projects. This research reviewed prior studies on SCV and adopted an appropriate definition that supports relevant decision-making on industrial construction projects. From this definition, the research objective is to develop detailed operational definitions of information needed to support supply chain decisions on industrial construction projects. The study employed mixed methods that consisted of interviews, review of mini-cases of industrial projects, procurement and material tracking tool assessment, and group discussions in structured workshops with a panel of subject matter experts. The research developed 79 detailed information needs and associated definitions that support ten key supply chain decision areas across detailed design, procurement, and construction phases of industrial construction projects. These definitions were evaluated by multiple means including an external team and a case study of an industrial construction project. The definitions developed by this research will enable both researchers and practitioners to invest in better measurements of visibility and support development of new tools and techniques.

Keywords: supply chain visibility1, information sharing2, construction supply chain3, industrialized construction4, supply chain decision-making5

\section{INTRODUCTION}

Supply chain visibility (SCV) refers to making informed decisions using the timely and accurate exchange of information between the participants as the materials move in the supply chain (Francis, 2008; Goh et al., 2009). Good SCV is found to improve coordination of material movement (Closs et al., 1997), increase agility and responsiveness of the supply chain (Patterson et al., 2004), reduce distorted information exchange (Dejonckheere et al., 2004), better inventory management (Huang and Gangopadhyay, 2004), and reduce costs (Huang et al., 2003). SCV is a common term and significantly researched concept in the broader supply chain domain (Caridi et al., 2014). Studies in general manufacturing, supply chain, and logistics community have documented topics such as defining SCV (Tohamy 2003; Francis 2008), measuring SCV (Caridi et al., 2010), quantifying benefits of improved SCV (Barratt and Oke, 2007; Caridi et al., 2014), and investigating operational activities in the supply chain that need visibility (Barratt and Oliveira 2001; Prater et al., 2005) to name a few.

The SCV of materials in industrial construction projects is reported to be low (Dharmapalan and O'Brien, 2018). These projects involve multiple supply chain participants who participate in varying 
capacities during the project's different phases (Caldas and Gupta, 2017). The materials required for such projects are often sourced world-wide and traverse through various supply chain locations before reaching the final installation point at the construction site. During this journey, materials go through a lifecycle of their own. They are designed, procured, fabricated, stored, loaded, transported, unloaded, consolidated, inspected, inventoried, packaged, and installed (Hunter, 2014). Supporting this physical flow, a large amount of information gets generated during the material's lifecycle (Lee et al., 2013). However, the supply chain participants only have easy access to the information within their organizational boundaries (Swaine et al., 2014). They need to exchange this information accurately and on-time with the other relevant participants to support decision-making in the supply chain. However, the exchange of information between supply chain participants is limited (Young et al., 2011). Even if there is an exchange of information, it is not always accurate, complete, on-time, and sufficient (Zhong et al., 2017). As a result, information sharing is ineffective, which, in turn, negatively impacts the decision-making process of stakeholders, leading to costly expediting, ineffective inventory management, out-ofsequence work, quality deficiencies, reduced productivity and safety (Kaming et al., 1998; Caldas et al., 2014).

To improve information exchange in the supply chain, the practitioner-oriented and academic literature in construction, so far, have examined and invested in Information Technology (IT) solutions that enable a digital exchange of information between supply chain participants (Young et al., 2011; Aram et al., 2013). Researchers have also examined the information flows of materials in the supply chain (Ergen and Akinci, 2008; Akcay et al., 2017) as well as used process mapping and modeling tools to visually depict material and information flow data (Arbulu and Tommelein, 2002; Akel et al., 2004; Fontanini and Picchi, 2004). While these efforts establish the need for visibility through information sharing, a detailed assessment of SCV is missing in the construction body of knowledge. This paper is part of a study that attempts to bridge this knowledge gap for capital projects in the industrial sector. The recent article by Dharmapalan et al. (2021) assessed the differences in viewpoints between owners, contractors, designers, and suppliers regarding the status of visibility at major supply chain locations and for common material types of industrial construction projects. The examination was based on data collected using a large-scale survey administered in North America and analysis of the survey data by the four stakeholder types. The current paper focuses on defining supply chain visibility (SCV) in detail for the industrial construction projects. There is limited understanding of how information exchange enables visibility. Specifically, the information is not well defined and fails to account for the supply chain participants' specific needs. Furthermore, there is limited knowledge about the supply chain's key decisions and what detailed information about materials is adequate to support the key decisions.

This study identified the key decision areas during detailed design, procurement, and construction phases of industrial construction projects. It also identified the information needs that support the key decision areas. Finally, the study developed detailed definitions of the identified information needs. To achieve these objectives, the study employed mixed methods that consisted of interviews, review of mini-cases of industrial projects, procurement and material tracking tool assessment, and group discussions in structured workshops with a panel of subject matter experts. The remaining sections of the paper are organized as follows. The literature review and research objectives are discussed in the following section. Next, the methodology section provides details on how the research was conducted. The results of the study and evaluation of the research findings are discussed in the results section. Finally, conclusions are drawn in the last section, including contributions and directions for future work.

\section{LITERATURE REVIEW}

Literature review involved understanding how supply chain visibility is defined in the broader business literature, followed by a review of information sharing and decisionmaking related research in the construction industry. The goal and research objectives which this research aims to fulfill is then presented.

\subsection{Supply Chain Visibility Definitions}

SCV originated in the general supply chain management and logistics domain, and it has multi-disciplinary roots in literature. So, the theoretical basis and supporting research on the concept are broad (Fawcett et al., 2007). A large body of research has focused on defining SCV. Table 1 provides a list of definitions of SCV.

Visibility is closely related to information sharing. Therefore, some researchers use both the terms interchangeably (Swaminathan and Tayur, 2003), implying that visibility is achieved through access and sharing of information. For example, Swaminathan and Tayur (2003) define visibility from an information availability and sharing viewpoint. Others, such as Bradley (2002), view visibility as a concept discussing software and IT solutions that enable information sharing within the supply chain. At the same time, some authors (Gustin et al., 1995; Closs et al., 1997) have argued that information availability and sharing is not sufficient for SCV and that it is essential to have accuracy, trustworthiness, timeliness, and relevance of the exchanged information. Barratt and Oke (2007) view visibility from a resource-based strategy; they contend that information sharing is the activity and that visibility is the capability that is the outcome of the activity. They further pointed out that visibility is viable through technology and non-technology enabled deployment of resources. McCrea (2005) moved beyond the simple information perspective and proposed a definition that views information as a triggering event, which leads to action. Goswami et al. (2013) define SCV from a decision-making perspective by linking information with decision-making purposes. Similarly, Tohamy (2003) and Goh et al. (2009) contend that availability and sharing of quality information (accuracy, trustworthiness, timeliness, usefulness) do not offer 
TABLE 1 | SCV definitions.

Author
Bradley (2002)
Swaminathan and Tayur (2003)
Barratt and Oke (2007)
McCrea (2005)
Goswami et al. (2013)
Tohamy (2003)
Goh et al. (2009)

\section{Definition}

\begin{abstract}
"Direct insight into the status of orders, inventory, and shipments across the supply chain"
"Ability to access/share information across the supply chain"

"The extent to which actors within a supply chain have access to or share the information which they consider as crucial or useful to their operations and which they consider will be of mutual benefit"

"The ability to be alerted to exceptions in supply chain execution and to enable action based on this information" "Having access to relevant information that can be used for various supply chain related decision making" "Capturing and analyzing supply chain data that informs decision making, mitigates risk, and improves processes" "The capability of a supply chain player to have access to or to provide the required timely information/knowledge about the entities involved in the supply chain from/to relevant supply chain partners for better decision support"
\end{abstract}

SCV automatically and that decision-making aspect needs to be considered.

The authors agree with the conceptualization of visibility by Barratt and Oke (2007), Tohamy (2003), Goswami et al. (2013), and Goh et al. (2009), and defined visibility for this study after them. Thus, visibility is the result of accurate, timely, and relevant information exchange about the state of materials between the stakeholders in the supply chain that enables decision making, risk mitigation, and process improvement. The authors adopted this definition since it is the union of crucial elements of the definitions by Barratt and Oke (2007), Tohamy (2003), Goswami et al. (2013), and Goh et al. (2009), and it captures the measurable attributes of visibility. While this definition states the need to have information that supports decisions, it cannot be readily applied to construction projects since it lacks the details about the information needs and the supported supply chain decisions. These two aspects of the construction industry are reviewed next.

\subsection{Information Sharing in Construction}

A stream of research has been performed to examine the information about materials that need to be exchanged and tools to aid information transfer. An example of information research is the work of Akcay et al. (2017). These authors documented the information flow of structural steel components in the supply chain to highlight the importance of information exchange and understand the steel supply chain's "design, fabrication, shipment, and erection" processes. The information generated and utilized the steel components' features including geometry, material characteristics, connections, and molding information (Akcay et al., 2017). Similarly, Ergen and Akinci (2008) identified and grouped the primary information flows for precast components that need to be shared in the supply chain. The leading information groups include "design information, material information, component quality control reports, and coordination information."

The area of research on tools has used IT to automate the transaction process of materials and facilitate the sharing of information about materials digitally between supply chain participants. For example, authors have used Radio Frequency Identification (RFID) (Song et al., 2006), integrated Global Positioning System (GPS) and handheld computers (Caldas et al., 2006), and also combined RFID and GPS (Torrent and Caldas, 2009) to improve visibility of engineered materials in the laydown yard of industrial construction sites. Similar technology combinations have also been used to improve the visibility of prefabricated materials in the storage sites at offsite fabrication yards (Ergen and Akinci, 2008). The information that is exchanged in electronic format includes information about "shipments, packing lists, inspections, purchase orders, fabrication progress, material receipts, material storage and location, material withdrawal requests, material pick and issue lists" (Dharmapalan and O'Brien, 2018).

While the current research highlights information flows and tools to facilitate their efficient transfer, the information items in these studies are not in detail, limited to specific problems within functions (procurement, material tracking, quality control), or capture data at specific locations in the supply chain and of certain material type. Also, the data provided by these studies is not flexible to the needs of the participants in the supply chain and fails to account for the dynamic nature of the construction industry (O'Brien et al., 2004), thereby causing inefficiency in the decision-making process. The importance of this decisionmaking aspect in the supply chain is discussed next.

\subsection{Decision-Making in the Supply Chain}

Decisions support an effective supply chain management of the flow of information, material, and funds. Previous research in construction (Arbulu and Tommelein, 2002; Elfving et al., 2002; Azambuja and Formoso, 2003; Polat and Ballard, 2003) have used models to visually depict supply chain configurations and provide insights for supporting decisions in the supply chain. As an instance, Arbulu and Tommelein (2002) applied Value Stream Mapping (VSM), a tool developed to represent flows of information and material, to support the evaluation of different supply chain configurations for engineered materials. Akel et al. (2004) and Fontanini and Picchi (2004) used VSM models and presented data about processes, material, and information on a more detailed level. While the authors of these studies contend that their results provide support for strategic, tactical, and operation level supply chain decisions, there is, however, no explicit mention of the decisions or decision areas.

Another body of research in construction focuses on decisions or a subset of decisions in the supply chain. Among such studies, Azambuja and O'Brien (2009) identified supply chain decisions that spanned across detailed design, procurement, and construction phases of a construction project. The detailed design consists of decisions regarding the configuration of the 


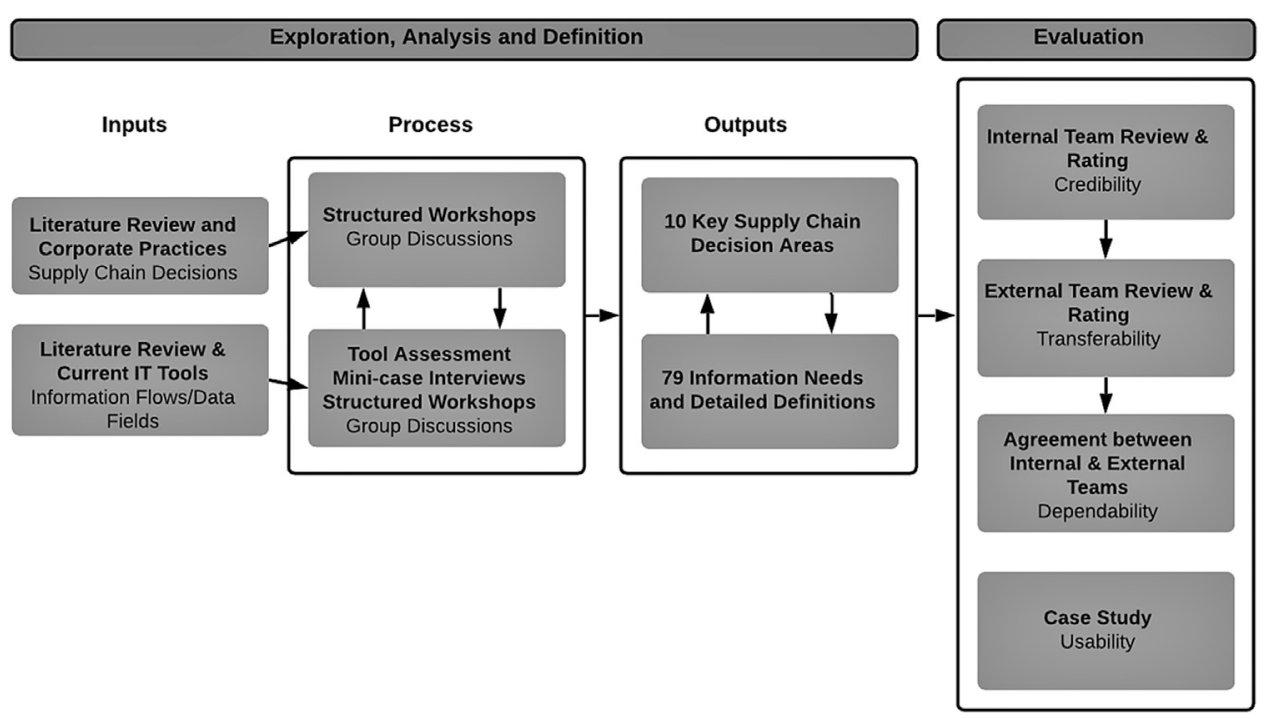

FIGURE 1 | Research process.

supply chain, systems' specifications, and decision regarding constructability. The procurement phase focuses on supplier selection and procurement decisions of materials. The construction phase involves decisions made to protect operations on the construction site from uncertainties in offsite production. In another study, Le et al. (2018) used the decisions by Azambuja and O'Brien (2009) as a basis and examined the decision-making aspect of the construction supply chain. The authors found that the extant literature focuses on twelve decision areas: "supply chain configuration, supplier selection, building partnerships, supply chain management tools, and methods, information systems, risk identification, production planning, purchasing materials, identifying transportation system, site layout planning, material handling, and controlling information flow." While these studies provide supply chain decisions, they are at a high level, skewed towards strategic decisions, and do not mention the information supporting the decisions.

In summary, the review of visibility definitions revealed that SCV encompasses a broader scope and depends on the efficient exchange of information between participants that enables actionable decisions. The extant literature in construction establishes the need for visibility; however, a detailed definition of visibility for advancement is unclear. Specifically, they do not provide information that presents the overall picture on various elements of the supply chain and have not considered supply chain participants' perspectives, which is useful for efficient decision-making. Furthermore, the decisions or decision areas supported by using the information provided by the tools and models are not well consolidated in literature. In other words, there is a need for systematic examination of the detailed information needs about materials and to link them to important decision areas in the supply chain to develop operational definitions of visibility. This study aims to achieve this goal by addressing the following objectives:
- Identify key supply chain decision areas for construction projects in the industrial sector

- Document, define and evaluate the detailed information needed to support the key supply chain decision areas

\section{METHODOLOGY}

The research process for the study is illustrated in Figure 1. The study used multiple research methods to accomplish the research objectives. A mixed approach was used since there were multiple research objectives and due to the dearth of studies in literature that has developed detailed operational definitions of visibility. The research process included two phases: 1) exploration, analysis, and definition; and 2) evaluation. This section describes each phase and the methods used within them in detail.

\subsection{Exploration, Analysis, and Definition}

The goal of this phase was two-fold: to identify the supply chain decision areas and; to document and define detailed information needs that support the identified decision areas. The identification of decision areas started with a review of literature and corporate practices. For the documentation of information needs, the authors used literature on information, data in current IT tools, and contextual mini-cases as the starting point. Next, the collected data for decision areas and the information needs were processed using structured workshops using a panel of subject matter experts. This sub-section provides details of the structured workshops and the assessment of current IT tools and mini-case investigation using the structured workshops.

\subsubsection{Structured Workshops Using Expert Panel}

Structured workshop is a useful method when the research involves multiple data collection strategies and the collected 
TABLE 2 | Expert panel background information.

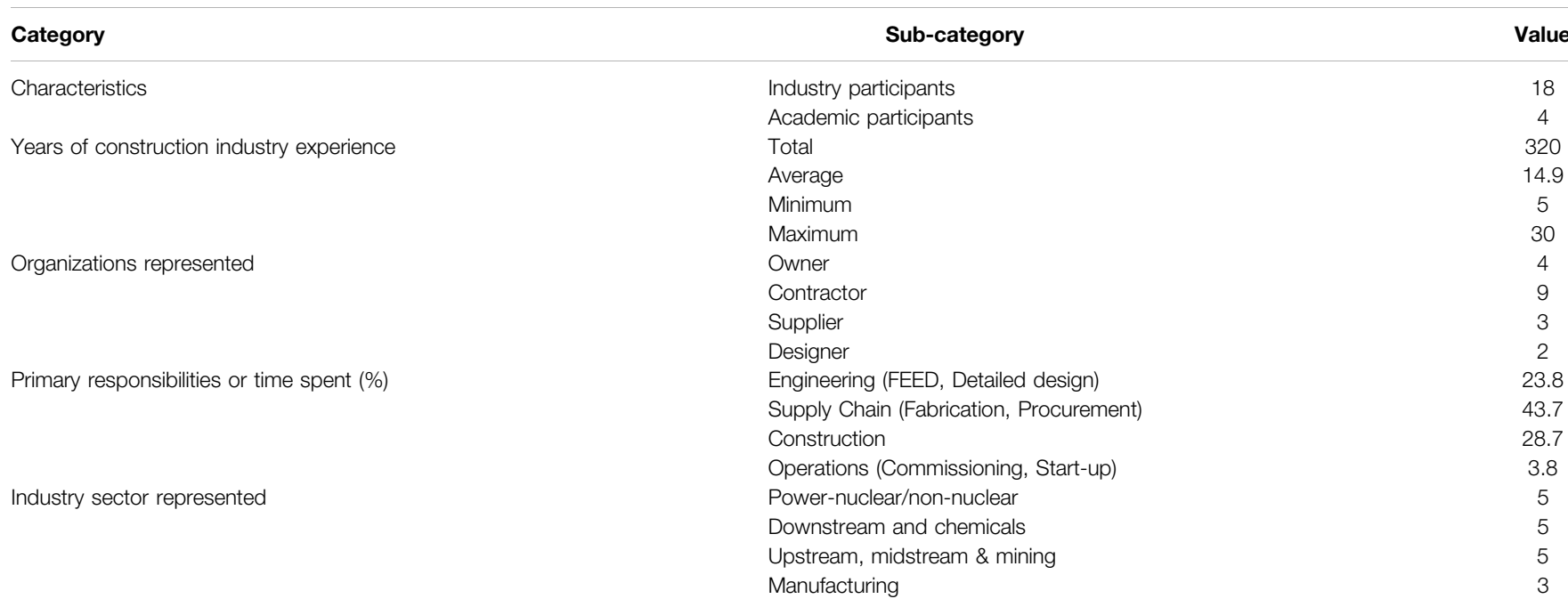

data needs to be expanded on using discussion between industry practitioners and academic researchers (Gibson and Whittington, 2010). Four academics comprising the authors facilitated these workshops with a panel of industry practitioners, who have experience in the industrial construction sector.

The industry practitioner's panel was chosen since lack of visibility in the supply chain is a practical problem. Additionally, the development of operational definitions of the information needed items required the viewpoints of industry participants. The panel included eighteen industry practitioners from four stakeholder types: four owners, nine contractors, two designers, and three suppliers. Table 2 provides the detailed background information of the subject matter experts. They had a total of 320 years of experience in industrial construction (mean = 14.9 years) and had worked on a variety of projects including power, downstream and chemicals, upstream, midstream and mining, and manufacturing. Also, the panel had spent $23.8 \%$ of the time in engineering, $43.7 \%$ of the time in supply chain, $28.7 \%$ of the time in construction, and $3.8 \%$ of the time in operations phase of industrial construction projects. The multiple stakeholder types and industrial project experience (overall and by phases) was important to the development of unbiased SCV definitions and to focus the research scope on projects belonging to the industrial construction sector. In addition to industry insight, the industry practitioners also assisted with data collection and were the source of industry practices and minicases that were used for the study.

The authors conducted the structured workshops using the protocol provided by Gibson and Whittington (2010). For this study, nine workshops were held over 1 year. Each workshop were 1.5 days long; the duration of first day was 8 hours while for the second day was 4 hours. The academic team divided the objectives of this study into smaller tasks that could be accomplished in each of the nine workshops. Before the start of the workshop, the academics shared a pre-read document with the industry expert panel. The document consisted of the workshop's agenda, details about the task or problem to be accomplished, and the resources required to understand and solve the task. These resources were inputs either from literature or from the industry panel or both (see Figure 1). Finally, during the workshop, these inputs were reviewed and discussed among the expert panel members. To encourage a thorough and unrestricted discussion, a no-objection rule was established early on and every panel member was provided an opportunity to give inputs. The discussions continued until majority or all of the team members reached consensus and the research objectives were accomplished. During the deliberations, the academic team took notes to record the minutes which were shared with the expert panel for verification. The process of using the workshop for processing information of tool assessment and mini-case investigation is explained next.

\subsubsection{Tool Assessment and Mini-Case Investigations}

The tool assessment aimed to review contractors' information tools (available commercially or developed in-house) to track materials in the supply chain and on the construction site. A structured questionnaire was used for the assessment. It consisted of questions that inquired about the tool's integration capabilities, application area (engineering, procurement, construction), and the data exchanged using the tool.

On the other hand, the mini-cases were based on actual ongoing or past projects in industrial construction from the expert panel's organizations. The case selection depended on the representativeness and specificity of the case, which are good attributes to uncover more information and gather insights (Yin, 2009). In this study, the mini-cases had conditions of information needs to support decision making in the supply chain of industrial construction projects. For each mini-case investigation, the academic team conducted one-on-one interviews with the industry expert and the personnel involved in the subject project. Multiple participants within the same project were interviewed. This helped in data's source triangulation and with the internal validity of the findings (Lincoln and Guba, 1985). A structured interview guide assisted in collecting data for the mini-case investigations. The questions of the guide focused 
on the following: understanding the project and the context that led to the supply chain decision(s), the information visibility that was available and that the project wished to have to support the decision(s), opportunities that were realized or missed as a result of the visibility (or lack thereof), the frequency and severity of the situation, and recommendation or lessons learned. The academic team took extensive notes and generated detailed case-study writeups. The academic team also collected additional supporting data about the case studies for review. These evidence sources included meeting minutes, procurement plan, expediting reports, material delivery reports, and project execution plans. Multiple sources of evidence helped in establishing data triangulation (Eisenhardt, 1989).

The analysis involved the examination of the individual minicase writeups. First, these writeups were shared with the interviewees. This verification of the writeups by the interviewees supported in achieving construct validity (Yin, 2009). Next, the academic team used inductive reasoning to analyze the cases. Inductive reasoning is part of the theorybuilding process. It is used to generalize findings of a phenomenon under investigation with the help of specific instances (De Vaus, 2001). Using the mini-cases' specific observations, the academic team generated an initial list of information needs that supported the decisions. The academics then presented the case reports and results to the expert panel during structured workshops. Throughout several workshops, the entire team further reviewed, refined, and finalized the list of information needs to support the decisions and develop detailed definitions for each of the identified information items.

\subsection{Evaluation}

This phase involved evaluation of the key supply chain decision areas, associated information needs, and definitions. The study used four ways to evaluate the research findings: internally by the expert panel, using an external team, assessing the level of agreement between the expert panel and external team, and using a case study.

\subsubsection{Expert Panel and External Team}

The evaluation by experts was conducted to establish credibility, transferability, and dependability (Lincoln and Guba, 1985). First, the research findings were evaluated by the internal expert panel. Using structured workshops, the researchers discussed the decision points and information needed items using prolonged engagement, triangulation (sources, methods, and investigators), and member checks (Lincoln and Guba, 1985). The evaluation by the internal expert panel improved credibility of the results. The collective review and feedback also augmented the authenticity of the research findings (Cresswell, 1998).

Next, the authors used an external team to evaluate the content and usability of the research findings. This was particularly important to check for transferability of the SCV definitions to other projects within the industrial construction sector. The external team included four owner, two contractor, and one supplier organization. Multiple participants within each organization participated in the evaluation. They had a total of 194 years of experience in the industrial construction (mean $=27.1$ years) and expertise in various industrial sector projects, including petrochemical, pharmaceutical, power, and manufacturing. Also, the distribution of their area of experience included engineering, procurement/supply chain, and construction phases of projects. The evaluation process involved the individual team participant check the decisions, information needed items, and the definitions for their comprehensiveness, quality, and confirmability (Lincoln and Guba, 1985).

\subsubsection{Agreement Between Expert Panel and External Team}

After the independent evaluation by the internal expert panel and external team, the authors evaluated the degree of consensus between the two groups. This assessment involved checking if there is an agreement among the two groups about the rankings of information needs and definitions. This process helped in evaluating the consistency of the research findings and to check if the findings are dependable (Lincoln and Guba, 1985). The agreement between rankings was checked using Kendall's Coefficient of Concordance (Kendall's W) (Schaeffer and Levitt, 1956). Kendall's W is a non-parametric test used when the data set is small and has many tied ranks (Field, 2009). The authors had both groups rate each information's importance level to rank the information needs using a 4-point Likert scale ( 1 = Low, $2=$ Medium, 3 = High, 4 = Critical). Next, each information-needed item's weighted mean score was calculated using the response numbers in each category (low, medium, high, critical) and the weights $(1,2,3,4)$ of the category. The information needs were then ranked by importance using the weighted mean scores and analyzed for agreement between the two groups using Kendall's W.

\subsubsection{Case Study}

The purpose of case study evaluation was to check the usability of the research findings (Lincoln and Guba, 1985). A single case was investigated since deductive reasoning was required to show that the set of information needed items is consistent with the investigated case project's information needs. Deductive reasoning is a theory-testing process and can be achieved using a single representative case study (Yin, 2009). It is used to check if the generalization or established theory can be applied to a specific instance (De Vaus, 2001). The investigated project was selected since it had an international supply chain and complex decision-making that needed visibility of materials across multiple locations and stakeholders. Also, the case encompassed multiple decision areas and several information items, thus meeting many requirements of the theory being tested (De Vaus, 2001). According to Yin (2009), such a case can provide moderate convincing test of research finding.

\section{RESULTS}

\subsection{Visibility Needed in the Construction Supply Chain}

\subsubsection{Key Supply Chain Decision Areas}

This study's first objective was to identify the key supply chain decision areas for construction projects in the industrial sector. 
TABLE 3 | Project phases and key supply chain decision areas within each phase.

\begin{tabular}{|c|c|c|c|}
\hline Phases & $\begin{array}{l}\text { Key supply chain } \\
\text { decision areas }\end{array}$ & Definition & KSCD \\
\hline \multirow[t]{5}{*}{$\begin{array}{l}\text { Detailed } \\
\text { Design }\end{array}$} & Detailing the construction sequence to get materials on site & $\begin{array}{l}\text { The ability to accelerate/decelerate the path of construction to ensure the right } \\
\text { materials are onsite at the required time }\end{array}$ & D1 \\
\hline & Reviewing long lead items and need dates & $\begin{array}{l}\text { This determines if the engineering sequence of critical components/long lead } \\
\text { items is compatible with the schedule }\end{array}$ & D2 \\
\hline & Identify materials/equipment requiring higher visibility & $\begin{array}{l}\text { The critical components/long lead items that need additional visibility based on the } \\
\text { nature of the material, confidence in delivery, and critical path }\end{array}$ & D3 \\
\hline & Establish supplier quality surveillance program and plan & Supplier progress, quality assurance, and control, schedule and performance & D4 \\
\hline & Use of catalog vs. custom & $\begin{array}{l}\text { The decision regarding standardized and customized materials to be used and } \\
\text { associated planning }\end{array}$ & D5 \\
\hline \multirow[t]{4}{*}{ Procurement } & Order long lead time products & $\begin{array}{l}\text { Ordering decision of critical materials that are long-lead items; the time to design } \\
\text { and fabricate is the longest }\end{array}$ & P1 \\
\hline & Supplier selection & $\begin{array}{l}\text { The selection of suppliers considering their location, organizational design, } \\
\text { handover, and interface management required }\end{array}$ & $\mathrm{P} 2$ \\
\hline & Expediting decisions considering overall project picture & $\begin{array}{l}\text { The acceleration, recovery, re-sequencing by monitoring materials/equipment } \\
\text { requiring high visibility }\end{array}$ & P3 \\
\hline & Order commodities/bulk & $\begin{array}{l}\text { Ordering decision of non-critical items that have a relatively shorter supply chain } \\
\text { period since they have a shorter lead time compared to critical items }\end{array}$ & P4 \\
\hline Construction & $\begin{array}{l}\text { Adjustment in schedule and supply chain to accommodate } \\
\text { materials flow disruption }\end{array}$ & $\begin{array}{l}\text { The decision during scope/design change that requires acceleration/deceleration/ } \\
\text { re-sequencing/recovery; starts with constraint management (reviewing } \\
\text { lookaheads), followed by expediting and recovery if constraints not met }\end{array}$ & C1 \\
\hline
\end{tabular}

The academic team provided a preliminary list of supply chain decisions identified by Azambuja and O'Brien (2009). The detailed design phase includes "defining products/technologies, constructability, modularization, prefabrication, evaluating supply chain configurations, and identifying risks." During the procurement phase, the decisions include the "order of long lead time products, make or buy products, selection of subcontractors and suppliers, geographical locations of suppliers, risk allocation via contracts, risk mitigation via capacity buffers using suppliers, and fixing of supply chain configuration." The construction phase involves "risk mitigation decisions via inventory and time buffers, inventory and time buffer sizes, locating inventory buffers, and risk mitigation via capacity buffers using subcontractors." These decisions provided a reasonable basis for the identification of key decision areas. Also, the industry panel members contributed examples of supply chain decisions that their respective organizations make during a project's lifecycle. In the end, the process led to the identification of more than fifty supply chain decisions across the following phases: initial conception, basic design, detailed design, procurement, and construction.

Next, the team reduced and finalized the decisions during one of the structured workshops. The process involved several rounds of review and refinement (add, deduct, modify) until the team members collectively arrived at a consensus on the list of decisions. During the review, the team members systematically checked each decision for logic and relevance. To aid the process, the team focused on the most important decisions and limited the scope to tactical and operational decisions that needed to be taken during execution once the supply chain was configured. This process reduced the decisions to thirty across the detailed design, procurement, and construction phases.

Furthermore, the team identified that some of the decisions were milestones (define products), processes (construction schedule logic), information (design information) within decisions. This led to combining many decisions and further reduced the list of decisions into ten key decision areas. Table 3 presents the final list of key supply chain decision areas (KSCDA) and their respective codes, organized by phase from detailed design through construction. These ten decision areas represent a complete set since they are the important ones consolidated from thirty decisions across detailed design, procurement, and construction and focus on tactical and operational level decisions during project execution. The detailed information needs that support these decision areas and their definitions are presented next.

\subsubsection{Information Needs and Definitions}

The second objective required developing and defining the detailed information needs that support the ten key decision areas. The team used findings from the literature, tool assessment, and mini-case studies to achieve this objective. First, the academic team shared and presented relevant studies in construction that examined information about materials generated or tracked in the supply chain. The studies by Ergen and Akinci (2008), Akcay et al. (2017), Song et al. (2004), Song et al. (2006b) were used as a starting point and facilitated the initial deliberations among panel members.

Next, the assessment of tools of industry practitioners provided information in their in-house procurement and material tracking tools. The authors interviewed five software vendors and seven contractor organizations. As part of the assessment, the participants also demonstrated their respective tools, contributed screenshots and relevant documents. This exercise informed the data fields about materials currently tracked as the material moves in the supply chain.

The results of the tool assessment revealed the following. First, there is a lack of standardization among the tools and inconsistency in material data tracked by companies over the 
TABLE 4 | Summary of case studies supporting information needed for key supply chain decisions.

\begin{tabular}{|c|c|c|}
\hline KSCDA & $\begin{array}{l}\text { Case } \\
\text { number }\end{array}$ & Project context \\
\hline $\begin{array}{l}\text { D3, } \\
\text { P1, P4 }\end{array}$ & CS1 & $\begin{array}{l}\text { Mid-life refurbishment of large power generation } \\
\text { facility - replacement of feeder pipes, fittings, and } \\
\text { tubes }\end{array}$ \\
\hline D1, P1 & CS2 & $\begin{array}{l}\text { Petrochemical project in the gulf coast of USA. } \\
\text { Total procurement spends: over } 200 \text { million on } \\
\text { national and international. Commodities included } \\
\text { fabricated equipment, piping, structural steel } \\
\text { (long lead items). Material needed to be ordered } \\
\text { according to the project schedule agreed with the } \\
\text { client and engineering progress }\end{array}$ \\
\hline $\begin{array}{l}\text { D2, } \\
\text { P1, P3 }\end{array}$ & CS3 & $\begin{array}{l}\text { Pipeline integrity program (6-36-inch pipeline and } \\
\text { valves) for a natural gas service provider. Valves } \\
\text { were sourced internationally from a pre-qualified } \\
\text { supplier list for pipes fabricated within the USA. } \\
\text { Outage dates drive fabrication and installation }\end{array}$ \\
\hline
\end{tabular}

D3, D4 CS4 Alloy fabrication for $1000 \mathrm{MW}$ combined cycle power plant in North America. The supplier was a domestic fabricator whose scope involved the fabrication and supply of pipe spools post-weld heat treatment as per specifications. A third-party inspection was required, and no material from

East Asia was allowed

P3, P4 CS5 $\$ 3$ billion petrochemical project in the Gulf Coast. European engineering and design firm had some procurement scope. U.S.- based contractor, had a lump-sum procurement and construction contract with the client. Grating fasteners initially furnished required substantial installation time and had high failure and rework rates. A new grating fastener system was introduced to mitigate the problems

P2 CS6 Final commissioning phase for an offshore production unit. A change in schedule made a piece of non-critical equipment into a critical package. The previous order was ineffective in meeting the requirements. The project technical team did not consult with the supply chain team (which had the global visibility of pre-approved and pre-qualified vendors) and engaged with non-qualified supplier

Custom colored couplings required by the client in Asia for 3000 MV power plant project for pulverized coal piping
Time and material contract - approximately 200 million. Milestone dates with incentives and liquidated damages. Extremely schedulesensitive project since it was one phase of a multiphase project. The owner controlled the material flow process. The decision was made by management to bulk issue all materials to the field to expedite the start of a project, meet schedule and early milestones

Problem

Material shortages, late deliveries, quality issues affecting the critical path. Tracking procurement and deliveries were challenging since numerous contractors were working on the project Detailed construction schedule was not ready; initial required-on-site (ROS) dates were estimated to drive bids and purchase orders (POs) of long-lead items; Additional labor costs in purchasing and expediting due to renegotiation with suppliers to revise $p O$ s as per schedule became more defined

Uncertainty in need dates due to non-defined outage dates; long lead times of valves challenged the fabrication of pipes and installation schedule; changed valve source (more expensive) for specific valves due to altered need dates; original valve supplier failed to deliver as promise

A large number of non-conformances identified at job-site due to material supply from East Asia; schedule deviations and subsequent quality issues to make up the schedule by the supplier

Quantity breakdowns and corresponding required-on-site (ROS) dates of new fasteners were not provided to the supplier. Material stock for the product in the U.S. was zero when the first $\mathrm{PO}$ and ROS date were finally provided to supplier. Quantity requested in the PO was the full order amount $-200,000$ fasteners. This required special production runs and air freight of products from Europe

Non-compliance of vendor prequalification during the selection process; engaged vendor without going through the process due to lack of internal visibility (silo problem) within the organization; non-involvement of the supply chain, and accelerating order placement without prequalification

Schedule constraints since the piping system was installed and were waiting on couplings; the EPC shared style and quantity of couplings with the supplier but not specialty paint information despite it specified by the owner; increased lead times due to late information of custom work

Bulk and inefficient distribution of materials to the field resulted in unaccountability and loss of materials. The productivity on the field was impacted as workers were spending time searching for materials

\section{Information visibility needed}

Information about materials on the critical path; procurement and delivery information of materials by the individual contractor; supplier information; schedule information Early information about construction work packages (CWP) and required-on-site (ROS) dates; transparency in production schedule and progress at suppliers

Defined outage information; detailed vendor reports; status and progress of valves in production, logistics, and inventory

Actual status and progress information from the supplier including early quality check information

Updated construction schedule information facilitates better material planning and deliveries. Improved detail and accuracy of component/material specifications eliminate ambiguous descriptions of "commodity" items

Internal collaboration and visibility: access to database of approved vendors; new vendor information and capabilities; schedule information

Project and paint specifications shared earlier from EPC's engineering team

Status, location, ownership of materials that were bulk issued 
TABLE 4 | (Continued) Summary of case studies supporting information needed for key supply chain decisions.

\begin{tabular}{|c|c|c|c|c|}
\hline KSCDA & $\begin{array}{l}\text { Case } \\
\text { number }\end{array}$ & Project context & Problem & Information visibility needed \\
\hline $\begin{array}{l}\text { D2, } \\
\text { D3, D5 }\end{array}$ & CS9 & $\begin{array}{l}\text { Turnaround project - Increasing approximately } \\
4,000 \mathrm{ft} \text { of overhead piping from } 24^{\prime \prime} 5 \mathrm{CR} \text { to } 30^{\prime \prime} \\
9 \mathrm{CR} \text {. The schedule was extremely critical since } \\
\text { the replacement had to be completed within the } \\
\text { turnaround schedule }\end{array}$ & $\begin{array}{l}\text { The client wanted specialty alloy for the 9CR } \\
\text { piping, which had a lead time of } 7 \text { months. The } \\
\text { compressed schedule of the turnaround project } \\
\text { as well as the specialty material requirement } \\
\text { made vendor selection and meeting project } \\
\text { requirements very challenging }\end{array}$ & $\begin{array}{l}\text { Design detail and dependencies for the } \\
\text { engineering team; potential suppliers and } \\
\text { lead time for procurement team; handling } \\
\text { and installation expertise for the } \\
\text { construction team }\end{array}$ \\
\hline
\end{tabular}

material lifecycle. Second, neither the reviewed procurement tools nor the material tracking software has independent capabilities to cover the entire supply chain or to track all the functions. For example, some are efficient at tracking procurement at the head office while not tracking data at construction sites. As such, almost all of these tools have isolated system capabilities (procurement, cost management, scheduling, material tracking) that do not exchange data smoothly, and also their integration process is challenging. As a result, much data is transmitted manually, which is prone to error. Third, the data tracked by the tools are static and not updated synchronously based on the changes on the construction site or in the supply chain. Therefore, the data is not always as per user requirement, which affects decision-making. These findings are in line with O'Brien et al. (2004) and O'Brien et al. (2005). Nevertheless, the academic team presented the findings during the structural workshops to support the deliberations about information needs and definitions.

Finally, the mini-cases also supported the deliberations during the structured workshops. The expert panel contributed nine cases (CS1-CS9) around the ten key supply chain decision areas; some cases related to more than one decision area. Table 4 provides an overview of the case studies. The key supply chain area related to the case is cross-indexed using the KSCDA codes. These cases included a variety of projects belonging to the industrial construction sector (oil and gas, power, mining, and metals), different sizes, and types (greenfield, brownfield, renovation). Each of these case investigations identified specific examples of the conditions that required visibility. Using the specific instances of each case, the academic team developed a general list of each decision area's information needs. This process of identifying the information needs using the minicases' specific information needs is explained next using the example of CS1.

\subsubsection{Case Study 1}

\subsubsection{Background}

The project pertains to the mid-life refurbishment of an enormous power generating facility based in North America. The project's scope included the replacement of feeder pipes, end fittings, pressure tubes, and calandria tubes.

\subsubsection{Visibility Problems}

Previous projects on refurbishment had revealed that the factors for poor project performance were a shortage, late deliveries, and quality issues of materials. Thus, it was imperative to drive the procurement of materials early; the process required setting milestone dates for items that are on the critical path far ahead of the installation dates so that these items are received and inspected onsite. This would remove a significant amount of risk of critical path items. However, numerous contractors were working on multiple projects across the nuclear refurbishment portfolio. The need to drive the procurement of materials meant having visibility into all the contractors' procurement and deliveries.

\subsubsection{Supply Chain Decision Areas}

The key supply chain decisions that can be induced from the project context are: to "identify materials and equipment requiring high visibility" since it was vital to document the items that are on the critical path for the project; and "order long-lead items and products" and "order commodity and bulks" to track the procurement and delivery of the items by the portfolio of projects and by contractors.

\subsubsection{Information Needs}

The information needs to support the three decision areas is depicted in Figure 2. The analysis of the interview data revealed specific information needs to support the three decision areas. For example, the decision area "identify materials and equipment requiring high visibility" is supported by project number, supplier number, purchase order issued, purchase order accepted, line items, and quantities. These information items are specific to CS1. Using these specific information instances, the academic team identified general information areas such that they are broadly applicable to challenges posed by limited visibility to make supply chain decisions. For example, the purchase order issued and accepted is categorized as purchase order information. Using these general information categories, the team documented the detailed information needed to "identify materials and equipment requiring high visibility.” Examples of detailed information needs under purchase order information include shipment quantities and special handling of materials. The remaining cases (CS2-CS9) were examined by following a similar process, which resulted in the detailed information needs for all the ten decision areas. The mini-cases examination led to the identification of more than hundred information needed items across the ten decision areas for the three phases.

Following the mini-cases analysis, the academic team presented the results to the industry expert panel during the 


\section{Case Study 1}

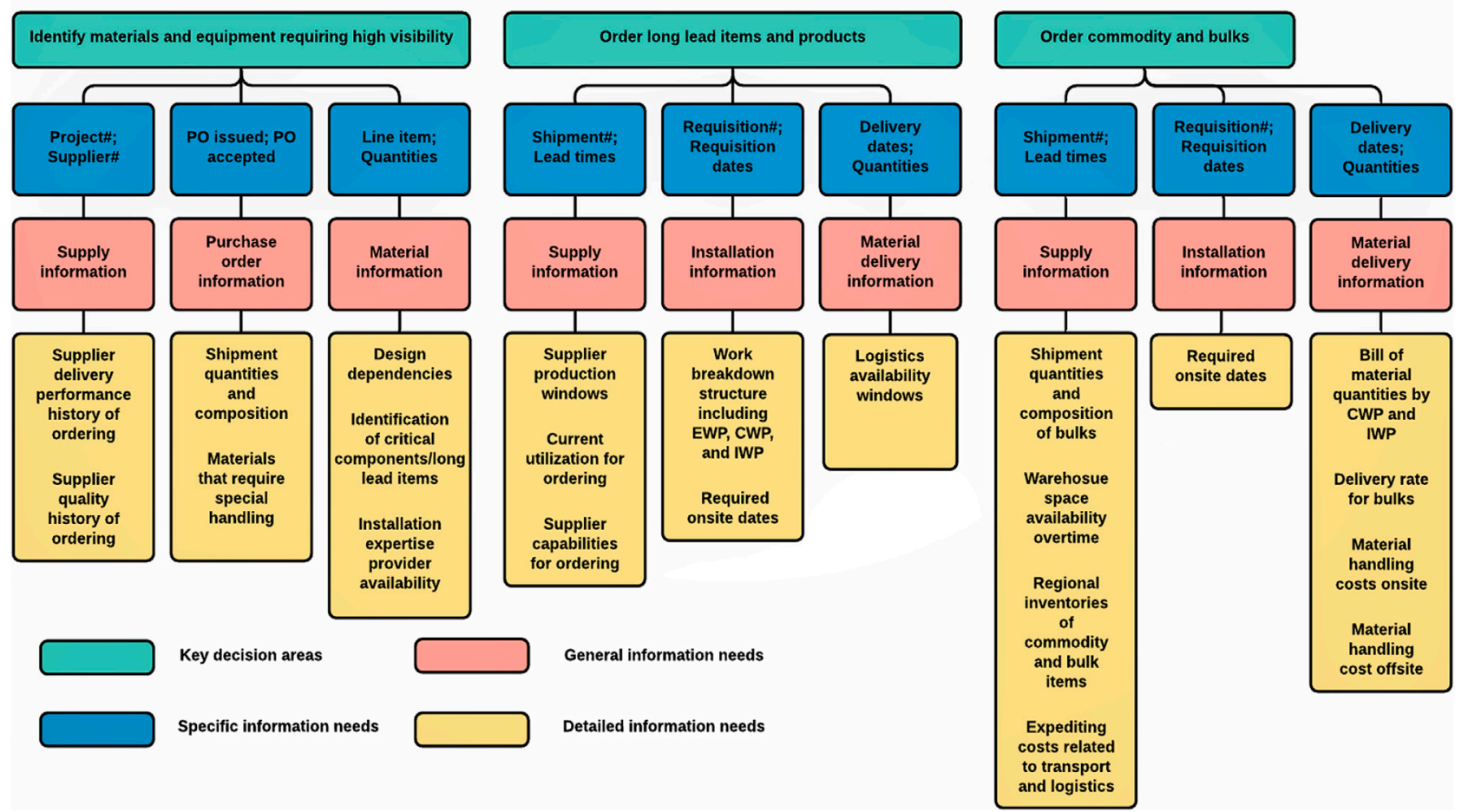

FIGURE 2 | Process of finding the detailed information needs to support key decision areas for mini-case CS1.

TABLE 5 | Information needed items and definitions for order commodities and bulk of Procurement phase (additional definitions for each phase in the Supplementary Appendix)

\section{Procurement}

\section{P4. Order commodities and bulk}

Bill of Material (BOM) quantities by CWP/IWP

Shipment quantities and composition - bulks (gaskets, pipes, bolts, etc.)

Required-onsite/Required-at-site dates

Warehouse space availability over time

Delivery rates for bulks

Regional inventories of common/commodity items

Expediting costs related to transport/logistics

Availability level/options of alternate supply source for common parts/ consumables

Materials handling costs offsite

Materials handling costs onsite
Detailed BOM quantities including systems and associated assemblies, components, subcomponents, consumables as per Construction Work Package and Installation Work Package Visibility into shipment quantities and how suppliers (and sub-suppliers) ship materials like pipes, gaskets, boltsetc.

The date needed onsite (or laydown/receiving yard) derived from the construction needed date plus the time needed to receive materials (including testing or assurance). May include a buffer between construction need date and date need to deliver to site (e.g., regulations may require a buffer) Allocation of warehouse space over time according to planned deliveries and installation of materials onsite that releases space

Valuation of delivery rate for bulks to validate work package/work plans and receiving requirements Information about the availability of regional inventories for common/commodity items. Used to assess the impact of a large order for bulk type materials that may exceed the suppliers' standard production capacity or stocking levels. It may be in conjunction with a frame agreement between contractor and supplier for delivery of bulk items. The availability of substitutes may also be monitored Transpiration and related costs to speed delivery of materials. This augments the cost/ability of the supplier to accelerate production

Alternate supply of common parts that can substitute for parts that are ordered (i.e., can substitute an alternate if the desired is unavailable)

Costs for materials handling, including storage costs offsite

Costs for materials handling, including storage, re-handling, and maintenance costs onsite structured workshops. In the workshops, the panel systematically reviewed each information need, modified it, and developed a detailed definition. This process involved checking the following:
1) if the information needed was indeed due to lack of visibility and not a project constraint/condition (e.g., country of origin requirements), or benefit/outcome of having good visibility (e.g., 
transparency using near-real-time access); 2) if the information needs were not broad or unclear (e.g., quality performance of suppliers); 3) if the decisions of the specific mini-case were supported by other information needs that were not apparent in the case; 4) if the information needs supported multiple decision areas; and 5) the definitions of the information needs were detailed and included perspectives from all: the owner, engineer, contractor, supplier, and technology vendor.

The entire process included multiple rounds of review and refinement. The reduction and finalizing of information needs and definitions took several workshops until there was collective consensus by the entire team. In the end, the team identified seventy-nine information needs across the ten key supply chain areas. Table 5 shows a sample by listing the ten detailed information needs and respective definitions that support the key supply chain area "P4: Order Commodities and Bulk." The full set of information needs and definitions for the remaining nine decision areas are given in the Supplementary Appendix.

\subsection{Evaluation}

The next phase of the research process comprises evaluating the credibility, transferability, dependability, and applicability of the decision areas, associated information needs, and definitions. The evaluation was conducted using the internal team, an external expert team, agreement between internal and external team, and case studies.

\subsubsection{Team Evaluations and Agreement}

Team evaluation included both the internal and external team evaluating the results of the study. This process involved checking each decision area, information needs, and definitions for quality, usability, and confirmability. This step also increased the content and construct validity of the research results. Five of the external participants also pointed out that the information needs and definitions can be used to audit their respective firms to get a snapshot of their current level of visibility on projects. Some of the external team members were curious about the research process that led to the identification and definitions of the information needed items. When explained, all of the seven external teams agreed that the use of multiple case studies as beneficial. As per them, the nine cases being complex in nature produces insights that can be applied to projects of equivalent and lesser complexity. Overall, the participants (internal and external) indicated that the research findings to be of high quality, complete in terms of information content required to support decision making on projects, and applicable in practical contexts within the industrial construction sector.

In addition, both groups also rated the importance of the information needs and definitions using the 4-point Likert scale. The Kendall's Coefficient of Concordance results indicates a high level of agreement between the two groups on the rankings of the information needs $(\mathrm{W}=0.885$, Chi-Square $=137.986, \mathrm{df}=78, p$-value $<0.0001)$.

\subsubsection{Evaluation Using Case Study}

The project investigated is a multi-billion-dollar oil and gas project in Canada. The case starts with the project background and an overview of the supply chain. Next, the visibility measures that were put in place are discussed. The analysis starts with identifying the decision area(s) critical to the case and the available supporting information, as well as comparing the identified decision area(s) and the information of the case with the set of decision area(s) and information needs from the research findings.

\subsubsection{Project Background and Supply Chain Overview}

The goal of the project was to boost the oil production in a region. The project involved the mining and extraction process of bitumen and scope of work included mine and site development, ore preparation plant, extraction, tailing and froth treatment facilities. The project had a cost-plus contract and an engineer-procure-construct (EPC) project delivery method. The supply chain of the project is depicted in Figure 3. The materials for the project were fabricated in multiple fabrication plants based in Asia. These included prefabricated small modules, stick-built, and bulk materials which were transported in 40-inch containers to the port in Asia. It also included pipe spools and steel that were part of a big module assembly program. All the materials were shipped to North America by sea. At the North American port, the materials traversed through different locations before reaching the project site for installation. First, the stick-built materials were transported by trailer trucks to a central staging yard. The smaller modules were transported directly to the project site for installation using trailer trucks. The other pre-fabricated and bulk materials were transported via rail to the central staging yard. The pipe spools and steel required for the big module assembly were transported to the staging yard and then to multiple modular yards managed by different contractors. Once assembled, these big modules were transported using heavy trailer trucks to the jobsite for installation. Bulk and ship-loose materials required for the module assembly were transported separately to the modular yards. The remaining materials that were part of the stick-built construction process were shipped directly to the site. This project was fast-tracked, and the modular assembly program was on the critical path of the schedule and consisted of more than 1,000 module packages.

\subsubsection{Visibility Problems}

Since the supply chain included multiple fabricators, ports, staging yard, laydown facilities, and warehouses (some even share between contractors), the information exchange process required a lot of cross-scope coordination involving the EPC, multiple contractors, and fabricators. The EPC's material management system lacked consistent and accurate data since there were at times voids of information material due to the unavailability of timely and accurate information from international vendors in the supply chain. There was missing information related to pipe supports and other bulk materials since the EPC did not load and track the relevant data in their material management system. In addition, it was a challenge to aggregate all the data and compile them for reporting purposes since all these stakeholders (five fabricators and four modular yards) had their own material management system and process. Next, the project included numerous heavy haul shipment coordination. Heavy haul items are materials that require a specialized over-sized trailer to transport materials that exceed certain dimension-length, width, height, or weight 


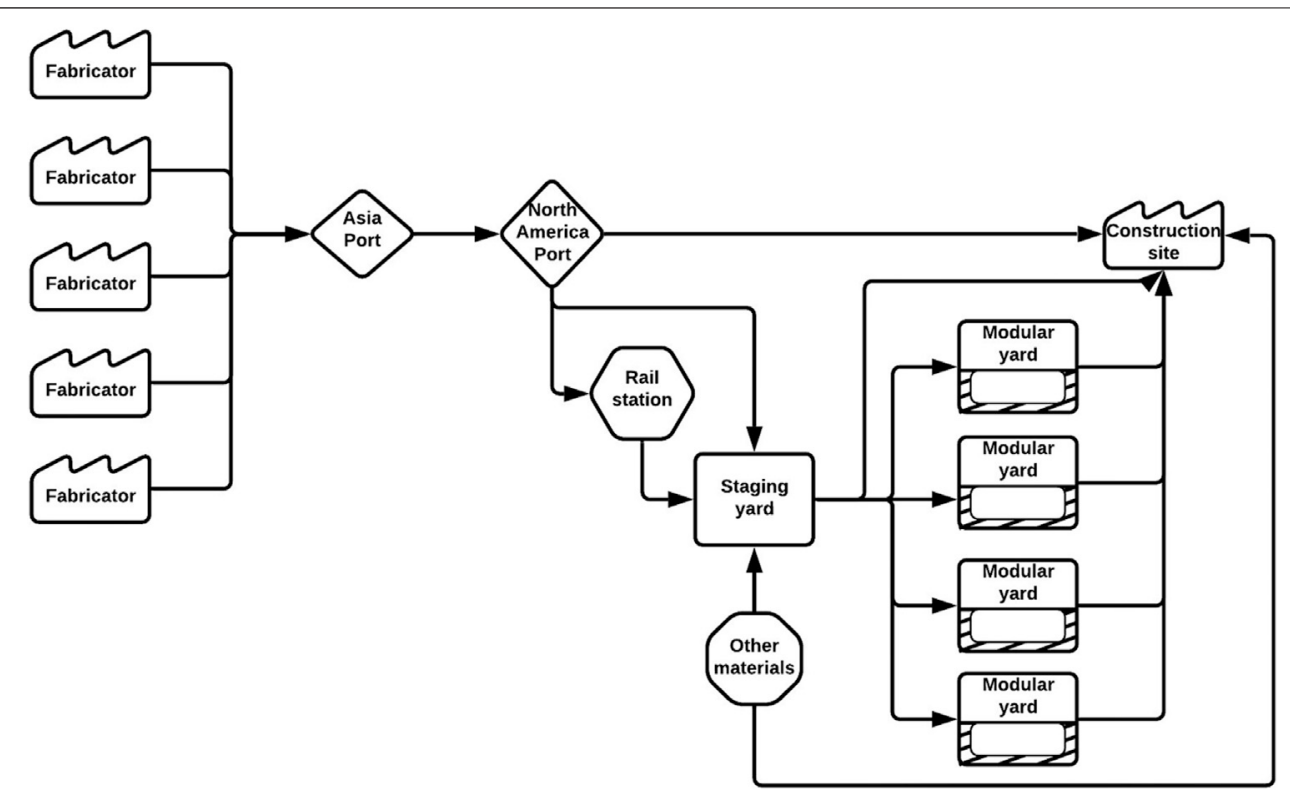

FIGURE 3 | Overview of the supply chain.

- or involves non-typical loading pattern. Each heavy haul shipment requires special coordination and permitting actions both on-site and throughout the supply chain process. The logistics carrier has to adhere to the regulations of any port of call, municipality, and transit authority involved in the transportation of the heavy-haul item. For example, small towns might have to close off their main streets or temporary closure of roads and bridges for a large heavy haul item to pass through. Last but not the least, the complex international supply chain made it difficult to track the disruptions of steel and pipe in the supply chain. All these highlighted problems resulted in an inefficient and cumbersome data-exchange. This, in turn, led to reactive decisionmaking based on outdated and static material information. In other words, there was a lack of visibility regarding materials at different points across the supply chain. For example, there was lack of owner visibility into challenges of materials readiness and workface planning across the multiple contractors giving rise to cost and schedule uncertainty.

\subsubsection{Visibility Measures on the Project}

Owing to the criticality of the modular assembly program, the owner mandated that the project pipe spools and steel piece-marks be barcoded and tagged using RFID. The application of these material tracking technologies was conducted at the port in Asia. The supply chain was also adjusted to enable a smooth material flow. In fact, the central staging yard was constructed in Canada to support the module assembly program. The project's supply chain process involved loading materials in removable racks in Asia by grouping them by modules. The packing list of the racks of materials were digitally created after physically scanning the materials into shipping containers, and the packing was done by work packages. After arrival in Canada, the racks were stored in the staging yard in Canada and shipped to the modular yards based on the material withdrawal request by the respective yards.

\subsubsection{Analysis and Discussion}

The expert panel reviewed the case study. The panel agreed that the module assembly installation could impact the schedule due to disruption of materials in the complex international supply chain. As such, the application of material tracking technologies was warranted. The system provided shipment data at the item and tag level to account for material flow disruption. Nevertheless, the panel perceived that the project needed more information about the following aspects.

First, there was no information about the modules after they were issued to construction. It would be helpful to know when and how many of the modules were installed in comparison to the construction need dates and purchase order (PO) quantities or bill of material (BOM) quantities. The construction need dates depend on the path of construction and differ by material types (long lead vs. bulks). Thus, identifying the long-lead items, the path of construction, shipment quantities and composition for engineered materials and major equipment packages is vital. Furthermore, information about constraint-free installation of the modules would provide visibility into quantities installed. These can be compared with either the PO or BOM information.

Second, the pipe supports and some bulks were not tracked using the materials management system. As per the panel members, pipe supports and bulks play an essential role in module installation. Therefore, visibility into shipment quantities and composition, warehouse space, delivery rates, and regional inventories, and expediting costs for bulks was required. This is especially important to plan for unplanned rush order of bulks if required at the later part of the project.

Third, the panel recognized that any delays in the project's progress and communications in the supply chain could result in 
TABLE 6 | Information available/needed for the project and associated decision areas.

KSCDA The information needed
for the project

D1 Upstream constraints at fabrication facilities

Construction sequence/path of construction

Current fabricator lead times for early planning

Logistics availability windows

D2

Identification of critical components/long lead time items

Shipment quantities and composition - engineered materials, major equipment packages

Required onsite dates

Logistics availability windows

P3

Construction need dates

Supplier production schedule

Finished goods inventory levels offsite

Finished goods inventory levels onsite

Logistics availability windows

Delivery rates for bulks

Regional inventories of common/commodity items

Expediting costs related to transport/logistics

Status and location of modules/materials in the supply chain at the tag and item level

Laydown space availability in staging yard, modular yards, warehouse over time

Supply chain's ability to hold inventory and delay deliveries

Client milestones

Bill of material quantities

IWP readiness including design, materials, labor, equipment etc.

Visibility into constraints in the fabrication yard release dates, modular yard schedule, fabrication yard, and tier-2 supplier contractual milestones

The general plan for construction sequencing, including work areas that supports plan for Construction work packages (CWPs)/Installation work packages (IWPs)

Current windows between ordering and delivery for components. May include sub-tiers of suppliers (upstream) for clarity

Shipping window/logistics constraint; e.g., limited availability of the heavy-lift capability Critical/long-lead components are identified through a review of Required-at-site (RAS) dates against purchase order $(\mathrm{PO})$ lead times; such components require early ordering to assure timely delivery to site. Critical/long-lead components set key procurement dates and may require extra monitoring. Critical components may also be identified as ones that have specific site installation dates that come from contractual milestones or key constraints such as limited availability of installation/expertise providers, weather windowsetc.

Visibility into shipment quantities as well as how suppliers (and sub suppliers) ship materials (e.g., major equipment, packages of equipment including sub-assemblies and parts. Also, loose components, spares, etc. of equipment that is designed and shipped by vendor) The date needed on site (or laydown/receiving yard) derived from the construction needed date plus the time needed to receive materials (including testing or assurance). May include a buffer between construction need date and date need to deliver to site (e.g., regulations may require a buffer)

Shipping window/logistics constraint; e.g., limited availability of the heavy-lift capability Installation date for materials on-site based on current information (Path of construction, schedule level of detail)

Supplier production plan and schedule (including incremental milestones) - constraints; cutting, welding, fit up, inspection etc.

Stock level of finished goods off-site at various supply chain nodes

Costs for materials handling, including storage, re-handling, and maintenance costs on-site Shipping window/logistics constraint; e.g., limited availability of the heavy-lift capability Valuation of delivery rate for bulks to validate work package/work plans and receiving requirements

Information about availability of regional inventories for common/commodity items. Used to assess the impact of a large order for bulk type materials that may exceed standard production capacity or stocking levels of the suppliers. May be in conjunction with a frame agreement between contractor and supplier for delivery of bulk items. Availability of substitutes may also be monitored

Transpiration and related costs to speed delivery of materials. This augments cost/ability of supplier to accelerate production

Near real time transactional information (status and location) of physical material as it traverses through different supply chain nodes as appropriately planned for the project (includes desired upstream nodes such as fabrication shops and 2nd tier suppliers; specification of extent of tracking is part of project planning). Must include BOM information for parent-child assemblies. Tags may need to be assigned upon receiving if common parts are shipped in quantity (bag and tag)

Allocation of laydown/warehouse space over time according to planned deliveries and installation of materials on-site that releases space

Ability of a supplier or logistics yard to hold additional inventory or delay deliveries. This can relieve the pressure on site storage needs. May be contractual

The dates set by client for key activities (e.g., start dates, turnaround windows, and required completions)

Detailed bill of material quantities including systems and associated assemblies,

components, sub-components, consumables as per CWP and IWP.

Visibility into IWP readiness to assure they are constraint free unplanned stockpiles of materials. Therefore, visibility into orders at offsite and onsite location, checking the ability of supplier/ fabricator to delay deliveries and/or of storage spaces (laydown, warehouses) if they can hold additional inventories is essential for effective inventory management. Fabricator's/supplier's ability to delay or hold deliveries, in turn, require information about upstream constraints, lead times, and production schedule of fabricators/suppliers.
Lastly, the panel commented that scope changes or change orders could impact the project. So, for the module program's success, the panel recognized that the project needed to manage constraints by continuously reviewing look-ahead schedules. Incase constraints are not met, then the project will have to expedite, recover the schedule, and readjust sequence to ensure timely and accurate delivery of materials. Constraint management, expediting, recovery, and re-sequencing are all 
part of the decision area C1- 'adjustment in schedule and/or supply chain to accommodate the material flow disruptions. The information required to support this decision area include readiness of installation packages, client milestones, status and location of modules and materials in the supply chain, BOM quantities, and supply chain's ability to hold or delay inventories. The above discussed information needs, their definitions, and the relevant decision area(s) are provided in Table $\mathbf{6}$. Table 6 is a subset of broader research findings of this study. This suggests that the case study is a good test of the decision areas and information needs.

The internal expert panel discussion revealed that the research findings provide a set of information needs and definitions which can be used in determining the information that is possible from the available data or the data conversion required using definitions that can facilitate a more efficient data exchange process. In other words, it can aid information to support decision making. For example, the material arrival and departure times (commonly tracked) can be used to calculate the inventory level of materials and space availability at supply chain locations. This information can be used to plan the delivery of modules from the Asia port as well as to ensure an effective inventory management in the staging area. This, in turn, can improve productivity in laydown yards and during installation and reduce both procurement and inventory costs. Thus, the applicability of the research findings in a real-world context indicates the practical value and use of decision areas and information needs.

\section{CONCLUSION}

Having visibility into the supply chain can result in more effective management and improved project performance. However, the construction literature lacks the definition of the detailed information needs in the supply chain that supports decision-making and enables visibility. This study developed and defined the detailed information to support key supply chain decision areas during detailed design, procurement, and construction phases for a typical industrial construction project.

The study contributes to the body of knowledge in two ways. First, the study defines ten key decision areas and 79 detailed information needed items, representing a significant advance to our understanding of information. This work was undertaken from the perspective of supporting decision making; development was performed by knowledgeable professionals as well as academics. The definitions are considerably more detailed and comprehensive than prior work in the area, whether from the perspective of academic literature or embodied in industry information tools. The input of multiple stakeholder types (owner, contractor, designer, supplier/technology provider) contributed to the quality of the definitions. Thus, the definitions collectively provide a unifying framework with a common vocabulary in the construction supply chain domain.

The second intellectual contribution is methodological. The study describes a rigorous process that can be used to develop detailed definitions of visibility. Many prior definitions of visibility in the general supply chain management and logistics literature have been conceptual. Other efforts are typically inductive from limited cases or deductive from first principals, but not both. This study describes both a deductive and inductive approach that uses the expertise of both academics and industry subject matter experts. While all of these elements have been seen in prior research, combining them to develop not just research findings but also practical definitions represent an advance for construction and related applied research.

The study also has practical implications. The set of information needs and definitions contributed by the study represents the user's desired information that is not fully available today. Therefore, the set of decision areas and information needs can be used by practitioners to augment their tools and procedures to better support projects. For example, the identified information needs and their definitions can be used to draft contracts along the lines of information needs on projects; this inclusion can help set expectations regarding information exchange between project participants early on during projects. Also, the information definitions can be used as a starting point to develop standardized definitions and needs statements that can help drive technology vendor implementations. Furthermore, practitioners can use the definitions as a common language to communicate with other stakeholders in the supply chain. The case study of industrial project used for evaluation in the current study gives some insight into how the definitions could be used in a real-world context.

This study provides an advance to our understanding and provides the groundwork for further research. One limitation of the current study is that the group of subject matter experts is based in North America and evaluation in other locations would help to generalize the findings. Similarly, the findings are centered in industrial construction and expansion to other sectors would be a worthwhile endeavor. That said, a focus on supporting decisions likely drives a set of information needs that is broadly applicable, particular for projects with complex supply chains as in the industrial sector. Second, while nine industrial construction project case studies contributed to the development of the research results, the study used a single case project to evaluate the research findings. Future research should investigate multiple case projects within industrial construction sector under different conditions to improve generalization and validation of the research findings. Another avenue of future work is using the defined information needs and supported decision areas as an evaluation framework of the SCV process. To achieve this, one way would be to identify the relevant SCV measurement variables for construction and using them to quantify the information needed items and decision areas. Quantification of the information items can also help in assessing the contribution of the individual information needs to the respective decision areas and to the overall SCV process. Beyond further expansion and validation of the findings, 
future research can utilize the definitions for more detailed assessment of supply chain visibility as well as a foundation for technical development. Similarly, practitioners can use the research to assess the limitations of their existing systems and prioritize augmentation using the research. Overall, the authors expect this research will be foundational in the development of more capable construction supply chains.

\section{DATA AVAILABILITY STATEMENT}

The original contributions presented in the study are included in the article/Supplementary Material, further inquiries can be directed to the corresponding author.

\section{ETHICS STATEMENT}

The studies involving human participants were reviewed and approved by the Institutional Review Board at The University of Texas at Austin. Written informed consent for participation was not required for this study in accordance with the national legislation and the institutional requirements. Written informed consent was obtained from the individual(s) for the publication of any potentially identifiable images or data included in this article.

\section{REFERENCES}

Akcay, E. C., Ergan, S., and Arditi, D. (2017). Modeling Information Flow in the Supply Chain of Structural Steel Components. J. Civil Eng. Manage. 23 (6), 753-764. doi:10.3846/13923730.2017.1281841

Akel, N. G., Tommelein, I. D., and Boyers, J. C. (2004). “Application of Lean Supply Chain Concepts to a Vertically-Integrated Company: a Case Study," in Proceedings of the 12th Annual Conference of the International Group for Lean Construction (IGLC-12), Denmark, August 3-5 2004, 560-574.

Aram, S., Eastman, C., and Sacks, R. (2013). Requirements for BIM Platforms in the concrete Reinforcement Supply Chain. Autom. in Constr. 35, 1-17. doi:10.1016/ j.autcon.2013.01.013

Arbulu, R. J., and Tommelein, I. D. (2002). Value Stream Analysis of Construction Supply Chains: Case Study on Pipe Supports Used in Power Plants. Proc. 10th Annual Conference of the International Group for Lean Construction (IGLC10), Brazil, August 6-8, 10, 183-195.

Azambuja, M. M., and Formoso, C. T. (2003). "Guidelines for the Improvement of Design, Procurement and Installation of Elevators Using Supply Chain Management Concepts," in Proc. 11th Annual Conference of the International Group for Lean Construction (IGLC-11th), Virginia, July 2003.

Azambuja, M., and O’Brien, W. (2009). “Construction Supply Chain Modeling: Issues and Perspectives," in Construction Supply Chain Management Handbook (FL: CRC Press Taylor and Francis Group), 2.1-2.31.

Barratt, M., and Oke, A. (2007). Antecedents of Supply Chain Visibility in Retail Supply Chains: A Resource-Based Theory Perspective. J. Operations Manage. 25, 1217-1233. doi:10.1016/j.jom.2007.01.003

Barratt, M., and Oliveira, A. (2001). Exploring the Experiences of Collaborative Planning Initiatives. Int. Jnl Phys. Dist Log Manage. 31 (4), 266-289. doi:10.1108/09600030110394932

Bradley, P. (2002). How Far Can You See. Logist. Manage. 41 (9), 27-34.

Caldas, C., and Gupta, A. (2017). Critical Factors Impacting the Performance of Mega-Projects. Ecam 24 (6), 920-934. doi:10.1108/ecam-05-2016-0117

Caldas, C. H., Torrent, D. G., and Haas, C. T. (2006). Using Global Positioning System to Improve Materials-Locating Processes on Industrial Projects.

\section{AUTHOR CONTRIBUTIONS}

All authors listed have made a substantial, direct, and intellectual contribution to the work and approved it for publication.

\section{FUNDING}

This research was funded by the Construction Industry Institute (CII) and is based on the project titled Improved Integration of the Supply Chain in Materials Planning and Work Packaging-Research Team (RT) 344.

\section{ACKNOWLEDGMENTS}

The authors would like to acknowledge the support of the industry expert panel members of RT 344, and the other firms that participated in the study.

\section{SUPPLEMENTARY MATERIAL}

The Supplementary Material for this article can be found online at: https://www.frontiersin.org/articles/10.3389/fbuil.2021.651294/ full\#supplementary-material

J. Constr. Eng. Manage. 132 (7), 741-749. doi:10.1061/(asce)07339364(2006)132:7(741)

Caldas, C. H., Menches, C. L., Reyes, P. M., Navarro, L., and Vargas, D. M. (2014). Materials Management Practices in the Construction Industry. Pract. Period. Struct. Des. Constr. 20 (3), 04014039. doi:10.1061/(ASCE)SC.19435576.0000238

Caridi, M., Crippa, L., Perego, A., Sianesi, A., and Tumino, A. (2010). Measuring Visibility to Improve Supply Chain Performance: A Quantitative Approach. Benchmarking 17 (4), 593-615. doi:10.1108/14635771011060602

Caridi, M., Moretto, A., Perego, A., and Tumino, A. (2014). The Benefits of Supply Chain Visibility: A Value Assessment Model. Int. J. Prod. Econ. 151, 1-19. doi:10.1016/j.ijpe.2013.12.025

Closs, D. J., Goldsby, T. J., and Clinton, S. R. (1997). Information Technology Influences on World Class Logistics Capability. Int. Jnl Phys. Dist Log Manage. 27 (1), 4-17. doi:10.1108/09600039710162259

Cresswell, J. W. (1998). Qualitative Inquiry and Research Design: Choosing Among Five Traditions. Thousand Oaks, CA: Sage.

De Vaus, D. (2001). Research Design in Social Research. Beverly Hills, CA: Sage.

Dejonckheere, J., Disney, S. M., Lambrecht, M. R., and Towill, D. R. (2004). The Impact of Information Enrichment on the Bullwhip Effect in Supply Chains: A Control Engineering Perspective. Eur. J. Oper. Res. 153 (3), 727-750. doi:10.1016/s0377-2217(02)00808-1

Dharmapalan, V., and O'Brien, W. J. (2018). Benefits and Challenges of Automated Materials Technology in Industrial Construction Projects. Proc. Inst. Civil Eng. - Smart Infrastruct. Constr. 171 (4), 144-157. doi:10.1680/jsmic.19.00009

Dharmapalan, V., O’Brien, W. J., Morrice, D., and Jung, M. (2021). Assessment of Visibility in Industrial Construction Projects: A Viewpoint from Supply Chain Stakeholders. Construction Innovation. doi:10.1108/CI-07-2020-0114

Eisenhardt, K. M. (1989). Building Theories from Case Study Research. Amr 14 (4), 532-550. doi:10.5465/amr.1989.4308385

Elfving, J., Tommelein, I. D., and Ballard, G. (2002). "Reducing lead Time for Electrical Switchgear," in Proceedings of the 10th Annual Conference International Group in Lean Construction (IGLC 10), August 6-8, Brazil, Citeseer, 237-250. 
Ergen, E., and Akinci, B. (2008). Formalization of the Flow of Component-Related Information in Precast Concrete Supply Chains. J. Constr. Eng. Manage. 134 (2), 112-121. doi:10.1061/(asce)0733-9364(2008)134:2(112)

Fawcett, S. E., Osterhaus, P., Magnan, G. M., Brau, J. C., and McCarter, M. W. (2007). Information Sharing and Supply Chain Performance: the Role of Connectivity and Willingness. Supp Chain Mnagmnt. 12 (5), 358-368. doi:10.1108/13598540710776935

Field, A. (2009). Discovering Statistics Using SPSS: (And Sex and Drugs and Rock " $N$ " Roll). Third. Thousand Oaks, CA: Sage Publications, Ltd.

Fontanini, P. S., and Picchi, F. A. (2004). "Value Stream Macro Mapping-A Case Study of Aluminum Windows for Construction Supply Chain," in Twelfth Conference of the International Group for Lean Construction (IGLC 12), , Denmark, August 3-5 2004, 576-587.

Francis, V. (2008). Supply Chain Visibility: Lost in Translation? Supp Chain Mnagmnt. 13 (3), 180-184. doi:10.1108/13598540810871226

Gibson, G. E., and Whittington, D. A. (2010). Charrettes as a Method for Engaging Industry in Best Practices Research. J. Constr. Eng. Manage., 136 (1), 66-75. doi:10.1061/(asce)co.1943-7862.0000079

Goh, M., De Souza, R., Zhang, A. N., He, W., and Tan, P. S. (2009). "Supply Chain Visibility: A Decision Making Perspective",in Industrial Electronics and Applications, 2009. ICIEA 2009. 4th IEEE Conference On, Xi an, China, May 25-27 2009 (IEEE), 2546-2551.

Goswami, S., Engel, T., and Krcmar, H. (2013). A Comparative Analysis of Information Visibility in Two Supply Chain Management Information Systems. J. Enterprise Inf. Manage. 26, 276-294. doi:10.1108/17410391311325234

Gustin, C. M., Daugherty, P. J., and Stank, T. P. (1995). The Effects of Information Availability on Logistics Integration. J. Business Logist. 16 (1), 1-21.

Huang, Z., and Gangopadhyay, A. (2004). A Simulation Study of Supply Chain Management to Measure the Impact of Information Sharing. Inf. Resour. Manage. J. (Irmj) 17 (3), 20-31. doi:10.4018/irmj.2004070102

Huang, G. Q., Lau, J. S. K., and Mak, K. L. (2003). The Impacts of Sharing Production Information on Supply Chain Dynamics: a Review of the Literature. Int. J. Prod. Res. 41 (7), 1483-1517. doi:10.1080/0020754031000069625

Hunter, R. (2014). Integrated Materials Management: A Value Driven Holistic Approach to Productivity Improvement Planning. Austin, Texas: Fiatech, 1-89.

Kaming, P. F., Holt, G. D., Kometa, S. T., and Olomolaiye, P. O. (1998). Severity Diagnosis of Productivity Problems-A Reliability Analysis. Int. J. Project Manage. 16 (2), 107-113. doi:10.1016/s0263-7863(97)00036-7

Le, P. L., Elmughrabi, W., Dao, T.-M., and Chaabane, A. (2018). Present Focuses and Future Directions of Decision-Making in Construction Supply Chain Management: a Systematic Review. Int. J. Constr. Manage. 20, 490-509. doi:10.1080/15623599.2018.1488089

Lee, J. H., Song, J. H., Oh, K. S., and Gu, N. (2013). Information Lifecycle Management with RFID for Material Control on Construction Sites. Adv. Eng. Inform. 27 (1), 108-119. doi:10.1016/j.aei.2012.11.004

Lincoln, Y. S., and Guba, E. G. (1985). Naturalistic Inquiry. Beverly Hills, California: Sage Publishing.

McCrea, B. (2005). EMS Completes the Visibility Picture. Logist. Manage. 44 (6), $57-61$.

O’Brien, W., Issa, R. R., and Flood, I. (2004). "Moving from Information Tunnels to Configurable, User-Model Driven Environments: A Vision for Future Project Information Technologies," in 4th Joint International Symposium on Information Technology in Civil Engineering, Tennessee, November 15-16. 1-10.

O’Brien, W. J., Issa, R. R., Shen, Z., and Xie, H. (2005). "Configurable Environments: a Vision for Future Project Information Technologies," in Knowledge Management in the Construction Industry: A Socio-Technical Perspective (Calgary, Alberta: Idea Group Inc.), 343-362.

Patterson, K. A., Grimm, C. M., and Corsi, T. M. (2004). Diffusion of Supply Chain Technologies. Transp. J.43(3), 5-23.
Polat, G., and Ballard, G. (2003). "Construction Supply Chains: Turkish Supply Chain Configurations for Cut and Bent Rebar," in Proceedings of the 11th Annual Conference of the International Group for Lean Construction, Virginia, July 2003.

Prater, E., Frazier, G. V., and Reyes, P. M. (2005). Future Impacts of RFID on Esupply Chains in Grocery Retailing. Supp Chain Mnagmnt. 10 (2), 134-142. doi:10.1108/13598540510589205

Schaeffer, M. S., and Levitt, E. E. (1956). Concerning Kendall's Tau, a Nonparametric Correlation Coefficient. Psychol. Bull. 53 (4), 338-346. doi:10.1037/h0045013

Song, J., Haas, C., Caldas, C., Ergen, E., Akinci, B., Wood, C., et al. (2004). Field Trials of RFID Technology for Tracking Fabricated Pipe - Phase 2. Austin, Texas: Fiatech, 1-57.

Song, J., Haas, C. T., and Caldas, C. H. (2006a). Tracking the Location of Materials on Construction Job Sites. J. Constr. Eng. Manage. 132 (9), 911-918. doi:10.1061/(asce)0733-9364(2006)132:9(911)

Song, J., Haas, C. T., Caldas, C., Ergen, E., and Akinci, B. (2006b). Automating the Task of Tracking the Delivery and Receipt of Fabricated Pipe Spools in Industrial Projects. Autom. in Constr. 15 (2), 166-177. doi:10.1016/ j.autcon.2005.03.001

Swaine, M., Becks, R., Hunter, R., and Joshi, P. (2014). "Moments of Truth in the Capital Project Network," in Presented at the Fiatech Technology Tuesday Webinar, August. available at: (accessed October 15, 2015)

Swaminathan, J. M., and Tayur, S. R. (2003). Models for Supply Chains in E-Business. Manage. Sci. 49 (10), 1387-1406. doi:10.1287/ mnsc.49.10.1387.17309

Tohamy, N. (2003). Supply Chain Visibility Defined. Cambridge, MA: Forrester Research.

Torrent, D. G., and Caldas, C. H. (2009). Methodology for Automating the Identification and Localization of Construction Components on Industrial Projects. J. Comput. Civ. Eng. 23 (1), 3-13. doi:10.1061/(asce)08873801(2009)23:1(3)

Yin, R. (2009). Case Study Research. Fourth Edition, Vol. 5. California, USA: Sage Publications, Inc.

Young, D. A., Haas, C. T., Goodrum, P., and Caldas, C. (2011). Improving Construction Supply Network Visibility by Using Automated Materials Locating and Tracking Technology. J. Constr. Eng. Manage. 137 (11), 976-984. doi:10.1061/(asce)co.1943-7862.0000364

Zhong, R. Y., Peng, Y., Xue, F., Fang, J., Zou, W., Luo, H., et al. (2017). Prefabricated Construction Enabled by the Internet-Of-Things. Autom. in Constr., 76, 59-70. doi:10.1016/j.autcon.2017.01.006

Conflict of Interest: The authors declare that the research was conducted in the absence of any commercial or financial relationships that could be construed as a potential conflict of interest.

Publisher's Note: All claims expressed in this article are solely those of the authors and do not necessarily represent those of their affiliated organizations, or those of the publisher, the editors and the reviewers. Any product that may be evaluated in this article, or claim that may be made by its manufacturer, is not guaranteed or endorsed by the publisher.

Copyright $(\odot 2021$ Dharmapalan, O'Brien and Morrice. This is an open-access article distributed under the terms of the Creative Commons Attribution License (CC BY). The use, distribution or reproduction in other forums is permitted, provided the original author(s) and the copyright owner(s) are credited and that the original publication in this journal is cited, in accordance with accepted academic practice. No use, distribution or reproduction is permitted which does not comply with these terms. 